EDITORIAL

\title{
Pathogenesis of acute rheumatic fever and rheumatic heart disease: evasive after half a century of clinical, epidemiological, and laboratory investigation
}

\section{E L Kaplan}

Heart 2005;91:3-4. doi: 10.1136/hrt.2004.034744

Rheumatic fever and rheumatic heart disease continue to be a problem for medical and public health communities the fact that penicillin has failed to eradicate this disease process is irrefutable proof of the need for more laboratory, epidemiological, and clinical research

T he report by Li and colleagues in this issue of Heart once again reminds both basic scientists and clinicians of the unsolved mystery of the pathogenetic mechanism(s) responsible for the development of rheumatic fever and rheumatic heart disease. ${ }^{1}$ These authors present observations implying a role for this virus in what they term "chronic, acquired valvar disease". While their report evokes questions about study design, methodology, and the relative paucity of firmly supporting data, nevertheless the concept must provoke thought. Li and colleagues' attempt to demonstrate a pathogenetic role for herpes simplex I as an agent in the development of rheumatic valvar heart disease falls short of establishing a relation. Additionally, the authors fail to adequately describe and take into account the sizeable body of evidence supporting the role for the group A $\beta$ haemolytic streptococcus (Streptococcus pyogenes). Rheumatic fever and rheumatic heart disease remain a significant cause of cardiovascular morbidity and mortality in countries around the globe even into the 21st century; it is a medical and public health problem which needs a solution.

This hypothesis is not the first time that a virus has been postulated to be pathogenetically related to rheumatic fever and its sequel, rheumatic heart disease. For example, among the many previous attempts to attribute rheumatic heart disease to viral infection were the reports in the 1960 s by the late George Burch and colleagues who described valvar lesions associated with coxsackie $\mathrm{B}$ virus infection in cynomolgus monkeys. They published intriguing photographs of mitral valve lesions in monkeys that were considered to be essentially identical to the early valvar lesions of acute rheumatic fever. $^{2-4}$ Twenty years later, Wedum-and later Peter Rowe-was enthusiastic about a viral contribution to rheumatic fever when she hypothesised a pathogenetic role for the measles virus in rheumatic heart disease, either alone or as a co-factor with group A streptococci. ${ }^{5}{ }^{6}$
Minneapolis, MN 55455

USA; kapla001@umn.edu
Numerous other more recent examples could be cited. Yet, similar to the present report, all still remain hypotheses.

\section{PATHOGENESIS OF RHEUMATIC FEVER}

Extensive reviews have been written about the pathogenesis of rheumatic fever and existing data have been exhaustively reviewed. The data supporting a role for the group A streptococcus as the triggering agent for development of rheumatic fever cannot be ignored. ${ }^{7}$ However, in concluding that currently available data are not sufficiently convincing about a role for viruses in the pathogenesis of rheumatic fever, one must be careful not to be intolerant of new concepts. It is clear that viruses may cause heart disease; viruses have been implicated in other forms of cardiovascular disease such as myocarditis and even atherosclerotic lesions to name only two. ${ }^{8} 9$ Autoimmune mechanisms have been postulated to account for cardiac damage. ${ }^{10}{ }^{11}$ But there is little to directly associate these viruses with rheumatic fever.

Historically there have been three major categories of hypotheses which have been promoted during the past five decades to explain a streptococcal pathogenesis for rheumatic fever. These include: (1) direct infection (for example, by the group A streptococcus); (2) effects of a streptococcal toxin (streptolysin $\mathrm{O}$ has been among the most commonly discussed); and (3) most feasibly, the concept of antigenic mimicry in association with an abnormal immune response.

During the past half century, it is the concept of antigenic mimicry and/or an abnormal immune response to group A streptococcal extracellular or somatic antigens which has been most interesting. The issue was concisely summarised in a recent review by Cunningham who commented: "The disease is autoimmune in nature and most likely results in part from the production of autoreactive antibodies." ${ }^{17}$ Yet, although many candidate group A streptococcal antigenic moieties have been investigated, none has been unequivocally demonstrated to be the inciting "culprit" or to fully explain the disease process.

\section{AUTOIMMUNE HYPOTHESIS}

Among the most widely promoted concepts in support of an autoimmune hypothesis involving the group A streptococcus has been the observation offered in the mid 1960s by Stollerman. Perceptively, he noted an intriguing epidemiological correlation between outbreaks of group A 
streptococcal upper respiratory tract infections associated with a relatively limited number of $\mathrm{M}$-protein types which were followed by outbreaks of rheumatic fever. In attempting to focus on an inciting factor, he used the term "rheumatogenecity" or "rheumatogenic M-types" to try to limit the number of streptococcal strains that might have the capacity to initiate the postulated immune response during the latent period between infection and onset of clinical disease. Reports such as the one by Kuttner and Krumweide more than 60 years ago, ${ }^{12}$ and other examples of an increased frequency with which a relatively limited number of specific M-types (for example, M-5, M-6, M-18) have been isolated during rheumatic fever outbreaks in communities, have provided support for a concept of enhanced rheumatogenecity and-by inference-suggesting antigenic mimicry. Yet, no investigation to date has incontrovertibly identified a/the "rheumatogenic factor". This lack of evidence has resulted in scepticism (perhaps healthy) about differences in rheumatogenecity among the more than 130 now recognised different $\mathrm{M}$ protein types of group A streptococci and has led some investigators to search for other inciting agents.

Multiple attempts to strengthen the available data explaining a streptococcal pathogenesis by identifying a specific animal model for the study of rheumatic fever and rheumatic heart disease have not been entirely successful. Numerous group A streptococcal somatic and extracellular antigens have been injected into multiple animal species and almost always have resulted in lesions, but none of the models have the combined clinical or pathologic features of rheumatic fever/rheumatic heart disease. The only recognised natural host (and reservoir) for group A streptococci is the human, and an appropriate animal model has not been identified in half a century. Thus, laboratory efforts to define a comprehensive concept of streptococcal rheumatogenecity have been severely hampered.

\section{MITRAL VALVE INVOLVEMENT}

An equally unsettling example when thinking about group A streptococci and antigenic mimicry is the fact that clinical studies have emphasised the overwhelming predisposition for involvement of the mitral valve. Embryologists remind us that all four valves develop from the same embryonic cell rest. If true antigenic mimicry involving heart valve tissue is responsible, would one not expect random involvement of and damage to all four heart valves in a random fashion? This observation must be answered before there can be unqualified acceptance for the antigenic mimicry hypothesis?

To omit the role of human host genetic or acquired variability in rheumatic fever susceptibility would be unwise. The concept of differing human susceptibility and human host factors was not addressed by $\mathrm{Li}$ and colleagues. ${ }^{1}$ That there is variation in how humans respond to group A streptococcal antigens has been recognised for many years. Despite clinical observations such as that by Pickles ${ }^{13}$ in the early 1940s, and numerous molecular based studies of the latter part of the 20th and 21st century, clinicians, epidemiologists, and basic scientists have been unable to adequately explain this influence. Studies such as those of Greenberg and colleagues leave little doubt about variation in the response to group A streptococcal antigens. ${ }^{14}$ Yet, many unknowns remain to be explained. For example, conceptually it has never been explained how five individual humans infected with the same-possibly pathogenetic-strain of group A streptococci respond differently to the antigenic challenge, unless unique host factors are also considered?
One of the five might have valvar involvement (carditis), another only arthritis (joints), a third chorea (central nervous system involvement), a fourth erythema marginatum (skin), and the fifth individual not develop any sequelae? What other interpretation is logical?

Even based upon the currently available incomplete data, I believe that there is little question about the pathogenetic role of the group A streptococcus in rheumatic fever! But until an encompassing prospective effort among epidemiologists, clinicians, microbiologists, immunologists, and other basic scientists can be initiated to provide more convincing data, speculation about the pathogenetic mechanism(s) will persist. As clinicians and scientists, until the exact mechanisms are known we must keep an open mind. Thus, even though investigative efforts like that reported by $\mathrm{Li}$ and colleagues $^{1}$ might be subjected to criticism, we are obligated to consider them.

\section{CONCLUSION}

The inability to solve this pathogenetic riddle about rheumatic fever represents more than simply the intellectual challenge. Available data confirm this cardiovascular disease to be a continuing problem for medical and public health communities even in industrialising countries. ${ }^{15}{ }^{16}$ It is very difficult to control any disease process until the pathogenetic mechanisms are understood. The fact that penicillin has clearly failed to eradicate this disease process is irrefutable proof to many of the need for more laboratory, epidemiological, and clinical research. Continuing investigation is imperative to either separate cardiac sequelae of these two vastly different microorganisms (group A streptococci and herpes simplex I) or to determine if the cardiac or valvar damage represents a similar form of end organ damage from two very different infectious agents. The challenge is obvious.

\section{REFERENCES}

1 Li Y, Pan Z, Ji Y, et al. Herpes simplex virus type 1 infection in rheumatic valvar disease. Heart 2005;91:87-8.

2 Burch GE, De Pasquale NP, Sun SC, et al. Experimental coxsackie virus endocarditis. JAMA 1966;196:349-52.

3 Sun SC, Sohal RS, Burch GE, et al. Coxsackie B4 pancarditis in cynomolgus monkeys resembling rheumatic heart lesions. Br J Exp Pathol 1967:48:655-61.

4 Burch GE, Sun SC, Colcolough HL, et al. Viral myocarditis and valvulitis identified in routine autopsy specimens by immunofluorescent techniques. Am Heart J 1967;74:13-23.

5 Wedum BG. Possible association between rubella vaccination and the decline in rheumatic fever. N Engl J Med 1985;312:991-2.

6 Rowe PC. Possible association of measles virus infection with rheumatic fever. N Engl J Med 1985;313:580-1.

7 Cunningham MW. Pathogenesis of group A streptococcal infections. Clin Microbiol Rev 2000;13:470-511.

8 Minick CR, Fabricant CG, Fabricant J. Atheroarteriosclerosis induced by infection with a herpes virus. Am J Pathol 1979;96:673-706.

9 Maisch B, Ristic AD, Portig l, et al. Human viral cardiomyopathy. Frontiers in Bioscience 2003;8:s39-67.

10 Pankuweit S, Portig I, Maisch B. Pathophysiology of cardiac inflammation: molecular mechanisms. Herz 2002;27:669-76.

11 Galvin JE, Hemric ME, Kosanke SD, et al. Induction of myocarditis and valvulitis in Lewis rats by different epitopes of cardiac myosin and its implications in rheumatic carditis. Am J Pathol 2002;160:297-306.

12 Kuttner AG, Krumweide E. Observations on the effect of streptococcal upper respiratory tract infections on rheumatic children: a three year study. J Clin Invest 1941;20:273-87.

13 Pickles WN. A rheumatic family. Lancet 1943;i:245-51.

14 Greenberg L, Gray ED, Yunis EJ. Association of HL-A 5 and immune responsiveness in vitro to streptococcal antigens. J Exp Med 1975; 141:935-43.

15 Veasy LG, Tani LY, Daly JA, et al. Temporal association of the appearance of mucoid strains of streptococcus pyogenes with a continuing high incidence of rheumatic fever in Utah. Pediatrics 2004;113:e168-e72.

16 World Health Organization. Rheumatic fever and rheumatic heart disease. Report of an Expert Panel. Geneva: WHO, 2004. 